\title{
Do North Sea cod (Gadus morhua) fisheries maintain high catch rates at low stock size?
}

\section{Rindorf, Anna; Andersen, Bo Sølgaard}

\section{Published in:}

Canadian Journal of Fisheries and Aquatic Sciences

Link to article, DOI:

10.1139/F08-086

Publication date:

2008

Document Version

Peer reviewed version

Link back to DTU Orbit

\section{Citation (APA):}

Rindorf, A., \& Andersen, B. S. (2008). Do North Sea cod (Gadus morhua) fisheries maintain high catch rates at low stock size? Canadian Journal of Fisheries and Aquatic Sciences, 65(9), 1800-1813.

https://doi.org/10.1139/F08-086

\section{General rights}

Copyright and moral rights for the publications made accessible in the public portal are retained by the authors and/or other copyright owners and it is a condition of accessing publications that users recognise and abide by the legal requirements associated with these rights.

- Users may download and print one copy of any publication from the public portal for the purpose of private study or research.

- You may not further distribute the material or use it for any profit-making activity or commercial gain

- You may freely distribute the URL identifying the publication in the public portal 


\section{Do North Sea cod fisheries maintain high catch rates at}

\section{2 low stock size?}

3 Anna Rindorf $^{*}$ and Bo Sølgaard Andersen ${ }^{2}$

$4{ }^{1}$ Danish Technical University, Danish Institute for Fisheries Research, Charlottenlund Castle,

5 DK2920 Charlottenlund, Denmark, Email: ar@difres.dk

$6 \quad{ }^{2}$ Danish Technical University, Danish Institute for Fisheries Research, The North Sea Centre, P.O.

7 Box 101, DK9850 Hirtshals, Denmark, Email: bsa@difres.dk

$8 \quad$ *Corresponding author. Telephone: +45 339633 59, fax: +45 33963333

9 Key words: Density dependence, catchability, aggregation, North Sea cod 
11 Abstract: This study presents an investigation of the relationship between stock size of North Sea 12 cod and catch rates in seven commercial fishing fleets. The shape of the relationship was estimated 13 using a new model allowing both density dependent changes in catchability and bias in the 14 assessment biomass estimates. Catchability in fisheries targeting a mixed species composition either 15 remained constant or decreased with decreasing stock size whereas catchability in targeted cod 16 fisheries increased with decreasing stock size. However, even in the cases where catchability 17 increased, the change was insufficient to compensate for the decrease in stock size and catch rates 18 of all fleets decreased. Two factors which could lead to non-constant catchability were investigated:

19 the presence of a decoupling between stock size and density in high density areas, and the presence 20 of concurrent shifts in the spatial distribution of the cod stock and the cod fishery. No evidence of 21 the former was found but there was a northern shift in the spatial distribution of both effort and the 22 cod stock. 


\section{Introduction}

The stability of any exploited stock relies on the relationship between stock size and harvest rate. If harvest rate decreases with declining stock size, year to year variation in stock size is decreased and limited harvesting has a stabilising effect. In contrast, if harvest rate increases with declining stock size, any decrease in stock size is aggravated as the stock is further diminished by exploitation, and the probability of collapse of the stock is increased. Harvest rate in fish stocks is usually regulated by restricting total landings, effort exerted and a number of technical measures such as gear type and mesh size. The restriction of fishing effort is based on the implicit assumption that catchability is constant. However, catchability in several fisheries increases with decreasing stock size (Rose and Leggett 1991; Rose and Kulka 1999; Swain et al. 1994), presumably by targeting local areas where density remains high (Paloheimo and Dicke 1964; Crecco and Overholtz 1990; Rose and Leggett 1991). The increase in catchability often leads to an increase in harvest rate as catch rate remains high (hyperstable) at low stock size giving the fishing fleet the potential to destabilise a small stock further. Knowledge of the presence or absence of a relationship between stock size and catchability is thus crucial when attempting to predict the effect of different effort management measures, a task which is required on a yearly basis for a great number of exploited stocks. Accuracy in the predictions is particularly important at low stock sizes, a situation in which data quality may be deteriorating due to misreporting and low catch rates in surveys.

A stock which is currently at a historic low due to the combined effect of fishing and changing climatic conditions is the North Sea cod (Gadus morhua) stock (O’Brien et al. 2000; Beaugrand et al. 2003; ICES 2006). In addition to the severe decline in stock size, the stock has exhibited changes in spatial distribution and is now distributed more northerly than previously (Perry et al. 2005; Rindorf and Lewy 2006). Furthermore, the area inhabited by juvenile cod seems to have contracted as stock size decreased (Blanchard et al. 2005). The stock would thus appear to 
48 have the potential to exhibit a highly undesirable combination of decreasing stock size and increasing catchability due to a contraction and change in location of the inhabited area. However, it has not yet been investigated whether catchability in the commercial fisheries has actually changed or whether any changes can be linked to a relatively constant density of cod in high density areas. This problem is particularly relevant as catch rates of cod are now regulated through limitations of both total catch and effort.

The objective of this study was to investigate the relationship between stock size and catchability of North Sea cod. The study was divided into three parts: Firstly, the relationship between stock size and catch rate in seven commercial fisheries was investigated to determine whether catchability changed with stock size. Secondly, the relationship between the change in the spatial distribution of cod and fishing effort was examined to determine whether cod related fisheries have followed the northwards shift in distribution of the population or has retained its historic distribution. Finally, the relationship between stock size and survey catch rates in high density areas was investigated to determine whether the presence of a relationship between catchability and stock size could be explained by constant high densities in these areas.

\section{Materials and methods}

\section{Stock size}

Stock size of North Sea (ICES areas IV, IIIA and IIVD) cod is estimated each year by ICES (ICES 2006). The biological assessment is based on reported landings, estimates of discard and age compositions of both landings and discards. In addition, catch rates in the $1^{\text {st }}$ and $3^{\text {rd }}$ quarter International Bottom Trawl Surveys (IBTS) are used to tune the assessment. In recent years, concern about the reliability of the reported total landings has led to the adoption of a modified assessment where total landings in the years 2000 to 2005 are adjusted by a yearly factor accounting 
71 for unaccounted mortality due to e.g. unreported landings. This factor is determined by a comparison between stock numbers and catch rates in the IBTS. Commercial catch rates are not used to tune the cod assessment, and though they contribute to total landings, it is unlikely that the catch rate of an individual fleet will affect the assessment. Hence commercial catch rates can be compared directly to assessment derived estimates of stock biomass without introducing a bias in the analyses whereas catch rates in the IBTS surveys are intrinsically linked to the assessment and therefore can not be used to determine the actual relationship between stock size and survey catch rates.

\section{Catch and effort data}

The catch in numbers per hour of each agegroup taken by two English fleets (English trawlers and English seiners) were derived from the assessment report (ICES 2006). These catch rates include discard estimates (ICES 2006) and hence provide direct estimates of catches rather than just landings. Estimates of biomass caught per unit effort were derived from catch numbers multiplied by the weight at age in landings (also given in ICES 2006). The catch per unit effort of English trawlers was available for the years from 1978 to 2005 whereas catch per unit effort of English seiners was only available up to 2001. Later years were therefore excluded from the analyses for this fleet. Though catch per unit effort of three Scottish fleets are also given in the reports, previous analyses (Cook and Armstrong 1985) has demonstrated that a historical change in the areas fished has led to severe changes in catchability of Scottish fleets. Hence, the differences seen in catchability are not directly related to stock size and these fleets were not examined. Effort and cod landings of five Danish fleets (small trawlers, large trawlers, small gillnetters, large gillnetters and Danish seiners) was estimated from a combination of vessel data, sales slips and official logbook records. In addition to date and location of each trip, the Danish logbooks provide information on vessel size, gear used, mesh size, weight and value of landings by 
species for each ICES statistical rectangle $\left(1^{\circ} \mathrm{W}\right.$ and $0.5^{\circ} \mathrm{N}$, Fig. 1$)$ and number of effort days for each fishing trip. Effort days are defined as days from the first fishing day to the day of entering the landing harbor. Both variables have been mandatory in the Danish logbooks since 1983. As a vessel can fish in several ICES rectangles during a trip, the effort of a trip is allocated to the ICES rectangle from which the highest catches (by value) were taken. Trips and vessels with missing or abnormal information and vessels with income below the economic criteria defining a fulltime fisherman were removed from the data set (Ulrich and Andersen 2004). Subsequently, the most important cod related fleets were defined from a combination of main gear deployed (type and mesh size) and vessel length (Table 1).

The trawl fisheries are mixed species fisheries targeting cod, other demersal fish species and Norway lobster (Nephrops norvegicus), species which are generally caught together. Including all fishing trips rather than merely trips catching cod has the advantage that trips which do not catch cod due to low abundance are included. Unfortunately, this means including trips operating in areas where cod could not have been caught even if abundance was high (uninhabitable areas). Though such areas may exist, cod has historically been abundant throughout the North Sea and the latter problem was therefore considered to be minor whereas the former problem had the potential to influence results greatly. Based on these considerations, it was decided to include all trawl and seine fishing trips regardless of whether cod was caught. In contrast to this, the gear type, deployment and choice of fishing area of the gillnet fisheries depends heavily on which species is the target. The target species or net type is not recorded in the official logbooks but retrospective analysis of the catch composition indicated that there was a clear separation between catches consisting primarily of cod and catches consisting of flatfish (Ulrich \& Andersen, 2004). Therefore, a cod-directed fishing trip for the gillnet fleets was defined as a trip where the cod was the dominating species by value (Table 1). These trips covered over $90 \%$ of the total cod landings of gillnet fleets. This 
method assured that catch rates were based on one gear type and deployment only but suffered the disadvantage that low catch rates are likely to lead to a categorisation of the trip as non-cod fishery and hence near-zero catch rates are likely to be discarded.

As estimates of discards are unfortunately not available at a disaggregated level for the Danish fleets, the average amount of cod caught per unit effort by a particular fleet in a given year and quarter was estimated as total landings (kg cod) divided by total effort. Only data from the North Sea proper (Fig. 1) in the years 1983 to 2005 were used.

\section{Survey catch per unit effort}

The catch at age in numbers per hour in the $1^{\text {st }}$ quarter International Bottom Trawl Survey (IBTS) is given in the assessment report (ICES 2006). From this, the total weight of immature and mature cod caught per hour of trawling was estimated by multiplying catch in numbers at age by weight at age in the stock (also available in the assessment report) and maturity at age, and then

131 summing over ages. Catch rate of all cod was estimated as the sum of immature and mature. In 132 contrast to commercial catch per unit effort series, catch rate in $1^{\text {st }}$ quarter IBTS survey was used to tune the assessment (ICES 2006) and this survey is therefore not independent of the assessment.

134 Hence, the correlation between catch per hour in the IBTS was given for comparison but it was not 135 attempted to estimate changes in catchability as the assessment was based on an assumption of 136 constant survey catchability (ICES 2006).

\section{Cod density in high density areas}

138 If cod concentrate in high density areas as biomass decreases, catch rate in these areas will not 139 be proportional to stock biomass. If these high density areas are then targeted by the fishery, 140 hyperstability of catch rates will occur. To investigate whether a decoupling of local density and 141 stock size occurred, cod density in high density areas was estimated from catch rates in the $1^{\text {st }}$ 
quarter IBTS survey (ICES International Bottom Trawl Survey Database, 1983 to 2005). The survey uses demersal trawls and length composition and total catch is recorded in each haul. Haul duration generally varies between 0.5 and 1 hour, and all catch rates are standardised to hourly values. On average, two trawl hauls are conducted within each ICES statistical rectangle (Fig. 1). Cod age-length keys were estimated using the method suggested by Rindorf and Lewy (Rindorf and Lewy 2001; Gerritsen et al. 2006; Rindorf et al. 2007). This method uses the correlation between length groups to determine smooth functions between length and the probability of being of a given age and is particularly useful to determine age length keys in cases with sparse sampling (Rindorf and Lewy 2001) as has been the case with larger cod in recent years. Number of each age group caught per hour was estimated by applying the estimated age length key to length distributions of the catch. Survey catch rate of mature cod and immature cod within each statistical rectangle (Fig. 1) was estimated by multiplying survey catch rate in numbers at age by weight at age in the stock (given in ICES 2006) and maturity at age (ICES 2006) and then summing over agegroups. Total survey catch rate of cod was estimated by summing the catch rate of immature and mature cod.

High density areas were defined as the $10 \%$ of statistical rectangles which supported the highest average survey catch rates in a given year. These areas were selected for separately total and mature cod, and the average total and mature cod survey catch rate within these high density areas was estimated. Hence, the actual rectangles included were not necessarily the same in all years or for total and mature cod. This method was chosen to avoid the problems caused by using a spatially

161 explicit area while the distribution of the stock is changing and the distribution of immature cod 162 differs from that of mature.

\section{Catch composition}


ICES (2006) divided by the total catch. The Danish catches were not sampled for age within individual fleets and instead the distribution of the catch weight on commercial landing size classes of cod from 1987 to 2005 was used. These size classes were divided into immature (<2 kg), mature ( $>4 \mathrm{~kg})$ and a mixture of mature and immature fish (2-4 kg) and correspond roughly to cod of age 1 to 2 , age $4+$ and age 2 to 4 , respectively. The proportion mature in these agegroups are $<0.05,>0.62$ and 0.05-0.62 (ICES 2006).

\section{Comparisons of catch per day and stock biomass}

We used a flexible model to describe the relationship between catch rates and stock size:

$$
U=a B^{(1+b)}+c
$$

where $U$ is catch rate, $B$ is stock size and $a, b$ and $c$ are constants. This model includes increasing catchability at decreasing stock size $(b<0$ and/or $c>0)$, decreasing catchability at decreasing stock size ( $b>0$ and/or $c<0)$ as well as constant catchability $(b=c=0)$ (Fig. 2). As a special case, it includes the power function often used in the literature $(c=0, b \neq 0)$ (Bannerot and Austin 1983; Harley et al. 2001). Furthermore, it includes the case where density remains relatively constant in areas unavailable to fishing (e.g. refugia) even when biomass is severely reduced. This leads to catch rates reaching zero at a biomass greater than zero $(c<0)$. Assuming $b=0$ for simplicity, the biomass

of fish in refugia is $-\frac{c}{a}$ as 


$$
U=a\left(B+\frac{c}{a}\right)=a B+c
$$

196 Further, the model includes the case where the true amount of fish, $B$ ', corresponds to the amount 197 estimated scientifically $(B)$ plus a bias of $\frac{c}{a}$. The bias term may be either positive or negative, 198 corresponding to scientific under- and over-estimation of biomass, respectively. Underestimation 199 could be the result if a constant amount of fish were unavailable to scientific surveys but remained 200 available to commercial fishing. This could occur if fish residing in areas with large rocks or around 201 wrecks were unavailable to survey trawls but available to commercial fisheries using stationary gear 202 such as hooks or gillnets. The commercial fishery then catches a constant proportion $a$ of the true 203 biomass per unit effort:

211 Note that the change in catch rate caused by the presence of refugia can not be separated from that 
caused by over-estimation of the stock (both lead to $c<0$ ). An intercept smaller than zero should 213 therefore be followed by detailed investigations before drawing conclusions regarding the state of 214 the stock.

Equation (1), denoted the full model in the following has the advantage that the different models of catchability (power function, refuge and bias models) are nested and statistical testing is therefore straightforward. To our knowledge, no other studies have included all these models in a formal test. The full model (eq. 1) was used to analyse the relationship between catch per unit of effort in both commercial fleets and the high density area survey $(U)$ by replacing of $B$ with either total $(T)$ or spawning stock biomass $(S)$ (both in units of $10^{9} \mathrm{~kg}$ ), depending on which of these exhibited the highest correlation with catch per unit effort. The parameters $a, b$ and $c$ were estimated by minimising the residual variation (sum of squares) of the full model. $b=0$ and another with $c=0$. If these reduced models both provided a significant increase in residual variation (F-test), the final model was equivalent to the full model and parameters $a, b$ and $c$ estimated. However, if setting either $b=0$ or $c=0$ led to no significant increase residual variation (Ftest), the parameter ( $b$ or $c$ ) with the lowest F-value (highest probability of being insignificant) was removed from the model. This reduced model was then compared to a model where $b=c=0$, and if this reduction did not deteriorate the fit of the model significantly (F-test), the final model was reduced to $U=a B$. The procedure is based on the assumption that the error in stock and spawning 231 biomass derived from the assessment is zero or at least negligible compared to that in catch rate. As 232 the assessment is based on total catches, the age composition of catches and survey catch rates and 233 hence integrates information from several sources, this assumption appeared reasonable. The 234 parameters of non-linear models $(b \neq 0)$ were estimated using the NLIN procedure in SAS ${ }^{\circledR}$ whereas 235 linear models $(b=0)$ were estimated using the GLM procedure in the same programme (SAS 
236 Institute Inc. 2001). Residuals were tested for trends (Pearson correlation with year) and 237 autocorrelation, and their distribution tested for significant differences from a normal distribution 238 (Shapiro-Wilks test).

Unfortunately, restrictive quota regulations may lead to misreporting of both effort, catch, area fished and even vessel size if the catch is brought ashore by another vessel. This may lead to both bias and variation in the estimated catch rates - bias if the catch is not reported at all and variation if the catch is landed by another vessel or reported as being from another area. Hence both bias and variation may occur in years with restrictive quotas (according to ICES (2006), the years from 2001 and onwards). They will express themselves as either consistent directional deviations from the average relationship between catch rates and stock size or as increases in the variation around the relationship in years with restrictive quotas. Furthermore, technical improvements in fishing power are likely to have occurred over the time span of the study. An increase in fishing power should express itself as an increase in catchability over time. The residuals were therefore examined to determine whether trends or increases in variance occurred.

\section{Distribution of survey catch rates and Danish fishing effort}

The spatial distribution of the Danish cod-related fishing effort was compared to the spatial distribution of the survey catch of mature cod per hour through an investigation of the relationship between the centre of gravity of survey catch rates and effort of each fleet in each year and quarter.

254 As catch per day in the Danish fleets consisted of a high proportion of mature fish and was 255 furthermore highly correlated to spawning stock biomass (see results), the centre of gravity of effort was only compared to the centre of gravity of survey catch rate of mature cod. The centre of gravity

257 of mature cod was estimated from the average catch of mature cod per hour in the IBTS in each statistical rectangle in the $1^{\text {st }}$ quarter of 1983 to 2006 and the $3^{\text {rd }}$ quarter of 1991 to 2005 . The $3^{\text {rd }}$ quarter survey was initiated in 1991 and thus covers only part of the period. The centre of gravity in 
260 a given year and quarter was estimated as the average latitude and longitude weighted by the natural $261 \log$ of $(1+$ the average catch of mature fish (in $\mathrm{kg})$ in each statistical rectangle, $\mathrm{sr}\left(0.5^{\circ}\right.$ latitude 262 times $1^{\circ}$ longitude) $), \ln \left(C_{s r}+1\right)$. This estimate of the centre was used for survey catches to obtain a 263 homogenous error structure (Rindorf and Lewy 2006). To avoid bias due to differences in survey 264 coverage, only rectangles fished in at least $80 \%$ of the years were used. This resulted in 169 and 161 265 rectangles in the $1^{\text {st }}$ and $3^{\text {rd }}$ quarter, respectively. The centre of gravity of cod-related fishing effort 266 of a particular fleet in each year and quarter was estimated as the average latitude and longitude 267 weighted by days fished in each statistical rectangle. The Pearson correlation coefficients between 268 the coordinates (latitude and longitude) of survey and effort centres of gravity were estimated.

\section{Results}

\section{Development in stock size, effort and catch per unit effort}

Though a slight increase in biomass was observed in the late 1990's, this was followed by decline, and both total and spawning stock biomass has decreased severely over the past 25 years (Fig. 3). Effort has decreased contemporaneously, in particular over the past 10 years (Pearson correlations coefficients between year $(1994-2005)$ and effort $<-0.68(\mathrm{P}<0.05)$ for all fleets except Danish large trawlers, Fig. 4) and in 2005, the effort of most fleets was less than $25 \%$ of the maximum recorded since 1983, the exceptions being Danish small (45\%) and large (77\%) trawlers.

277 The majority of the reduction of effort can be explained by a reduction in the number of vessels. 278 Catch per unit effort series of most fleets show similar temporal patterns (Fig. 4).

\section{Catch composition}

More than $80 \%$ of the English catch per unit effort consisted of immature cod, whereas the 281 Danish catch generally consisted of a greater proportion of mature than immature cod (Fig. 5). 282 Around $40 \%$ of gillnet and seine catches consisted of mature cod and another $40 \%$ of a mixture of 
mature and immature cod, while the proportion of mature and mixed mature and immature in

284 Danish trawl catches was intermediate between these values and those of the English fleets.

\section{Comparisons of catch per unit effort and total stock and spawning stock biomass}

As expected from the catch composition, spawning stock biomass showed the highest correlation with catch per day for Danish fleets whereas total stock biomass showed the highest correlation to English fleets (Table 2). Note that in this table, 36 correlation analyses are performed (not including the IBTS). If the significance level is set to $5 \%, 5 \%$ on average will be termed significant due to type 1 error (detecting significant relationships where none exists). When examining 36 correlations, there is thus a greater than $5 \%$ probability of detecting up to 4 correlations significant at the $5 \%$ level (binomial probability $>0.05, \mathrm{~B}(36,0.05)$ ). At the $1 \%$ level, this is decreased to a greater than 5\% probability of detecting 1 or 2 significant correlations whereas at a significance level of $0.1 \%$, the probability of detecting 1 or more significant correlations by type 1 error is 0.035 . Therefore, four comparisons should be expected to be significant at the $5 \%$ level, two at the $1 \%$ level and none at the $0.1 \%$ level by type 1 error alone. In contrast to this, 26 correlations were significant at the $0.1 \%$ level for both total stock and spawning biomass and further 30 and 32 comparisons were significant at the 1 and 5\% level, respectively. Thus the number of significant relationships greatly exceeds that expected by type 1 error.

Eq. (1) was fitted to English catch per unit effort using total stock biomass as the independent variable and to Danish catch per unit effort using spawning stock biomass as the independent variable as these combinations showed the highest correlation (Table 2). The Danish seiners showed low correlations with both total and spawning stock biomass (Fig. 6, Table 2) and were excluded from further analyses. The parameter $b$ was significantly different from zero in five cases: English seiners, Danish small gillnetters in the $1^{\text {st }}$ and $3^{\text {rd }}$ quarter and Danish large gillnetters in the $1^{\text {st }}$ and $3^{\text {rd }}$ quarter (Table 3 ). In the English seiners, $b$ was larger than zero (the exponent was 
larger than 1) indicating increased catchability at large stock sizes (Table 3, Fig. 7). In contrast to 308 this, the value of $b$ found for Danish gillnetters was negative in all cases (the exponent was less than 309 1). The intercept was only significantly different from zero in two cases: Danish small trawlers in 310 the $3^{\text {rd }}$ quarter and English seiners (Table 3). Danish small trawlers showed negative intercepts in 311 both quarters, but only the $3^{\text {rd }}$ quarter value was significantly different from zero, indicating a 312 decrease in catchability at low stock sizes (Fig. 7). The intercept of English seiners was positive and 313 hence this fleet tended to retain catch rates at a certain minimum level in spite of decreases in stock 314 size corresponding to an increase in catchability at low stock sizes (Fig. 7). In summary, 315 catchability decreased with decreasing spawning stock biomass for Danish small trawlers in the $3^{\text {rd }}$ 316 quarter but increased with decreasing spawning stock biomass for Danish gillnet fleets. Catchability 317 of English seiners decreased with decreasing biomass, though this pattern seemed to reverse at low 318 stock sizes (Fig. 7). However, as the amount of data in the area where catchability supposedly 319 increases was limited, firm conclusions on this would require additional estimates of catch per unit 320 effort at low stock size.

The distribution of the residuals did not differ significantly from a normal distribution for any fleets except for Danish small trawlers and gillnetters in quarter 1, English trawlers and the high density surveys catch rates of total and spawning cod $(\mathrm{P}=0.0002, \mathrm{P}=0.0111, \mathrm{P}<0.0001, \mathrm{P}=0.0394$ and $\mathrm{P}=0.0003$, respectively). Only English trawlers exhibited significant trends in the residuals 325 ( $\mathrm{P}>0.05$, Table 3, Fig. 8). There does thus not appear to have been a general decrease in reported 326 catch per unit effort as a result of reporting only part of the landings but all of the effort. Neither 327 was there any indication of increased catchability due to technical improvements in any fleets except the English trawl fleet. Only Danish small gillnetters in the $1^{\text {st }}$ quarter exhibited significant autocorrelation of the residuals (correlation=0.48, $\mathrm{P}=0.0212$ ). 
First quarter survey catch rates in high density areas were highly correlated to both total stock biomass and spawning stock biomass (Fig. 9, Table 2). There was no indication of a nonlinear relationship as survey catch rates were proportional to the assessment estimates of biomass (Table 3).

\section{Comparison of centres of gravity of survey catches and commercial effort}

Latitude of the centre of gravity of survey catches of mature cod increased significantly in both the $1^{\text {st }}$ and $3^{\text {rd }}$ quarter (Table 4 ) indicating a northern shift in distribution. Contemporary to the shift in centre of gravity of survey catches, effort of all five Danish fleets moved northeastwards in the first quarter (Table 4). The pattern was less clear in the $3^{\text {rd }}$ quarter, as Danish trawlers moved south while Danish small gillnetters moved north. There was a general trend towards operating in more eastern waters in the $3^{\text {rd }}$ quarter in recent years (Table 4). Effort centres of gravity were closely related to survey centres of gravity for the Danish gillnet and Danish seine fleets in the $1^{\text {st }}$ quarter whereas effort centres of gravity of the remaining fleets were only weakly (but positively) related to survey centres of gravity in the same period (Table 4). In contrast to this, the correlation between effort and survey centres of gravity in the $3^{\text {rd }}$ quarter was only significantly positive for latitude of large trawlers and small gillnetters (Table 4). Hence, there was evidence that effort followed cod distribution in the $1^{\text {st }}$ quarter which is the traditional period among fishermen for targeting cod (pers. obs.), whereas there was only a tendency for effort to follow the latitude of cod distribution in two fleets in the $3^{\text {rd }}$ quarter. Note that as table 4 examines 44 correlation analyses, 5 should be significant at the $5 \%$ level, 2 at the $1 \%$ level and none at the $0.1 \%$ level by type 1 error

351 alone (binomial probability $>0.05, \mathrm{~B}(44, \alpha)$ ). However, of the 44 comparisons, 24 were significant at the 5\% level, 20 at the $1 \%$ level and 12 at the $0.1 \%$ level (Table 4), a much higher number than would be expected by chance. 


\section{Discussion}

We found no evidence of the presence of refuges, of concentration in high density areas or of constant bias in the scientific stock assessment. All fleets except one exhibited a clear relationship between catch rates and either total or spawning stock biomass. Catchability of several fleets changed with stock size and in two cases, the relationship between catchability and stock size was monotonically decreasing (corresponding to hyperstability of catch rates). However, in spite of this negative relationship, the fleets were unable to compensate for the severe decrease in biomass and catch rate of all fleets decreased as biomass diminished. Except from a barely significantly positive intercept for English seiners, there was no evidence from any of the fleets of positive intercepts corresponding to scientific underestimation of stock size. Further, only one fleet exhibited a significantly negative intercept corresponding to either fishing outside refuges or scientific overestimation of the stock.

Density in high density areas was tightly related to stock size in the North Sea and there was no evidence of non-proportionality. The lack of aggregation rendered the trawl fleets unable to maintain constant high densities and, generally, catchability remained constant in these fleets. 369 Gillnetters often target fish around wrecks and rocks, areas which may support dense fish aggregations (Gregory and Anderson 1997) and which are unavailable to demersal trawl gears. In 371 spite of this, catch rates of gillnetters showed a high degree of agreement with trawl catch rates 372 indicating that density in trawlable and non-trawlable areas co-varied. This agreement may even 373 have increased in later years as the development of more flexible ground gears has allowed the use 374 of towed gears on bottom substrates previously unavailable to trawlers. The co-occurrence of a northern shift in the spatial distribution of gillnet fishing effort and survey catch rates in the main fishing season also suggests that gillnet catch rates agree with survey catch rates. In contrast, the distribution of the stock in the $3^{\text {rd }}$ quarter inferred from survey catch rates was not generally related 
to the distribution of effort, indicating either that factors other than cod distribution affects the distribution of effort in this period or that the shorter time period contained less contrast in the centres.

Persistent high densities in some areas in spite of decreases in stock biomass have been found in studies of cod both in the northern Gulf of St. Lawrence and northern cod (NAFO areas 3Pn4RS and 2J3KL, respectively) (Rose and Legget 1991; Rose and Kulka 1999). Presumably as a result of this decoupling of local density and stock size, the catchability of the cod related trawl fishery increased in both stocks as stock size declined (Rose an Leggett 1991; Rose and Kulka 1999). Why the aggregative behaviour of North Sea cod differs from that of cod in other areas remains unknown. Possibly, the North Sea has fewer low-quality habitats as growth rates in this area have historically been high compared to other areas (Brander 1995). In any event, there was no evidence of aggregation or of increasing trawl catchability at low stock size.

Fleets with a diverse landing composition such as trawlers showed either no or positive relationships between catchability and stock size whereas specialised cod-directed fleets such as gillnetters showed negative relationships. This corresponds with what is expected from random sampling (trawling) and oversampling of high density areas resulting from cod being the target species (gillnetters). Contrasting results have been seen in other studies of catchability and stock size of cod as some authors have found inverse relationships between both commercial and survey catchability and stock size (Winters and Wheeler 1985; Rose and Leggett 1991; Swain et al. 1994) whereas others found no significant relationships, be it positive or negative (Harley et al. 2001, Hanchet et al. 2005). Though other authors have suggested that one common pattern for all fleets targeting a given species should exist (Harley et al. 2001), this seems unlikely as the tendency for catchability to increase at low stock size is increased by both the aggregative behaviour of the target species and the degree to which the fishery targets local high density areas (Paloheimo and Dickie 
1964; Hilborn and Walters 1992; Gaertner and Dreyfus-Leon 2004). The difference between the conclusions reached may reflect both differences in the aggregative behaviour of the stocks as well as in the motivation or ability of fishermen to target high density areas. However, the pattern of constant catchability in mixed species fisheries and increasing catchability with decreasing stock size in targeted fisheries seen here is likely to be general.

The results obtained here can not necessarily be generalised to all North Sea fishing fleets. Targeting behaviour and hence catchability is influenced by physical constraints such as vessel type and size, restrictions imposed by management regulation, vessel interactions, information sharing as well as skipper skills (Gillis et al. 1993; Gillis and Peterman 1998; Gaertner and Dreyfus-Leon 411 2004) and variation in these decision parameters between fleets and among fishermen within a fleet 412 will create both temporal and spatial diversity in catchability. Though it cannot be generalised to all 413 fisheries, the analysis does, however, present the first thorough multi-fleet analyses of North Sea 414 cod related fisheries and the fleets together cover a significant proportion of the cod landings. The increased catchability of gillnetters at low stock size could be the result of either an 416 increased aggregation of cod in non-trawlable areas, a correlation between effort allocation and 417 catchability of individual vessels, a gear saturation effect at high stock sizes or a relationship 418 between catch rates and effort recorded as cod-targeted. Increased aggregation in non-trawlable 419 areas seems unlikely as there is a fair agreement between gillnet effort distribution and survey catch 420 rate distribution, indicating that the two gear types provide comparable estimates of spatial 421 distribution and therefore most likely also of temporal distribution. A correlation between effort 422 allocation and catchability of individual vessels could occur if individual differences in cod catch 423 rates exists due to e.g. differences in skipper skills and gillnetters with low catch rates switch to 424 other fisheries at low stock size. This would lead to an increase in catchability as less efficient 425 vessels shift to other species or leave the fishery. Another explanation for changes in catchability 
which are unrelated to aggregation of the target species could be gear saturation. This would occur if gillnets become more visible and hence are more easily avoided once some cod have been entangled. To reveal whether this occurs would require detailed studies of density and avoidance behaviour around set nets. Lastly, a relationship between catch rates and effort recorded as codtargeted could be an artefact caused by the exclusion of gillnet fishing trips where cod was not the main economic species in the landing. Using this method, the gillnet fleet can maintain apparently stable catch rates at low stock size, as only those trips where sufficient cod were caught to obtain the majority of the landing value will be included in the estimate of catch per unit effort. Though this problems seem to arise due to the definition of cod directed fishing effort, using all fishing effort as done for the trawl fleets is not without problems either. In this case, one obtains an overoccurrence of low or zero catches of cod (corresponding to an overestimation of effort) as trawl trips performed in areas uninhabitable by cod and with different gear deployment are included. This problem is likely to increase as cod stock size decreases and more restrictive catch quotas decrease the motivation to target cod. Nevertheless, we believe the definitions used (targeted gillnet fishery and non-targeted trawl and seine fishery) present the least bias among the two alternatives, given that the actual species targeted is unknown.

The low correlation between stock size and catch rates observed in Danish seiners may be caused by several factors. Firstly, over $90 \%$ of the Danish seine vessels have been decommissioned during the study period (>500 in 1983 to 47 vessels in 2005), primarily due to a combination of a 445 dramatic decline in the quotas of both cod and other target species and a lack of cod in the southern 446 part of the North Sea where the majority of the Danish seine fleet traditionally had their home 447 harbour. Most likely, the decommissioning has caused a permanent loss of the least efficient vessels 448 (low catchability vessels) from the fishery. Furthermore, the Danish seine fishery in contrast to the 449 other Danish fisheries investigated is primarily a summer fishery and catch success depends heavily 
on weather conditions.

The residuals show no evidence of increased catchability (technical creep) or increased misreporting in later years. The fishery has been severely reduced since the implementation of the North Sea cod recovery plan in 2001 and this could have caused both bias and increased variation in reported catch rates within this period. They should have expressed themselves as either consistent directional deviations from the average relationship between catch rates and stock size or as increases in the variation around the relationship in years with restrictive quotas. Nevertheless, there was no tendency for variation in the residuals to increase or exhibit trends in later years (Fig. 8). Furthermore, there was only minor changes in the parameters of the models if the years from 2001 onwards were excluded from the estimation procedure (results not shown), and hence the results given here did not appear to be greatly biased by misreporting in later years.

As catch per unit effort of the modelled fleets was highly correlated to stock biomass, the fleets fulfil two of the requirements to an abundance estimate (unbiased residuals and high correlation). These catch per unit effort series may thus be the solution to the need for industrybased series of North Sea cod abundance as a supplement to survey series described by Horwood et al. (2006). However, for these series to be reliable, it must be assured that discard, misreporting of effort and catch and fishing power does not increase in the future.

A central question from a management point of view is whether any of the fleets examined here would seriously diminish the population if not regulated restrictively. Assuming that the total landings of each fleet provide reliable estimates of catches, this problem is evident by the observed increase in catch divided by total stock biomass as stock biomass decreased up to the year 2000 (Fig. 10). Note that catch of a fleet divided by total stock size is proportional to the partial fishing mortality induced by that fleet if the ratio between average weight of cod in the catch and in the stock remains constant. The severe decrease in total allowable catch appears to have reduced at least 
official landings per biomass by about $50 \%$ whereas the regulations prior to this period does not appear to have reduced fishing mortality. Though ICES suggests that the decrease in the observed fishing mortality may partly have been abated by a larger unspecified mortality in later years (ICES 2006), Horwood et al. (2006) estimated a decrease in cod fishing effort of 37\% from 2000 to 2004.

The discrepancy between these two estimates of cannot be explained at present. However, it is clear that in the absence of the severe reductions in total allowable catch, there would have been a further increase in fishing mortality as stock size decreased, thereby accelerating the decline of the already threatened cod stock.

\section{Acknowledgements}

This work was funded by the national project REX1 (funded by the Danish Ministry of Food,

Agriculture and Fishery), and of the EU project CAFÉ (Capacity, F and Effort). The results and 485 conclusions drawn do not necessarily reflect the views of the sponsors. Clara Ulrich and two anonymous referees provided valuable comments on an earlier draft.

\section{References}

Bannerot, S. P., and Austin, C. B. 1983. Using frequency distributions of catch per unit effort to measure fish abundance. Trans. Am. Fish. Soc. 112: 608-617.

Beaugrand, G., Brander, K. M., Lindley, J. A., Souissi, S., and Reid, P. C. 2003. Plankton effect on cod recruitment in the North Sea. Nature 426: 661-664.

Blanchard, J. L., Mills, C., Jennings, S., Fox, C. J., Rackham, B. D., Eastwood, P. D., and O’Brien,

C. M. 2005. Distribution-abundance relationships for North Sea Atlantic cod (Gadus morhua): observation versus theory. Can. J. Fish. Aquat. Sci. 62: 2001-2009.

Brander, K. 1995. The effect of temperature on growth of Atlantic cod (Gadus morhua L.). ICES J. Mar. Sci., 52: 1-10. 
Cook, R. M., and Armstrong, D. W. 1985. Changes in catchability of cod, haddock, and whiting associated with the Scottish seine-net fleet. J. Cons. Int. Explor. Mer 42: 171-178.

Crecco, V., and Overholtz, W. J. 1990. Causes of density-dependent catchability for Georges Bank haddock Melanogrammus aeglefinus. Can. J. Fish. Aquat. Sci. 47: 385-394.

Gaertner, D. and Dreyfus-Leon, M. 2004. Analysis of non-linear relationships between catch per unit effort and abundance in a tuna purse-seine fishery simulated with artificial neural networks. ICES J. Mar. Sci. 61: 812-820.

Gerritsen, H. D., McGrath, D., and Lordan, C. 2006. A simple method for comparing age-length keys reveals significant regional differences within a single stock of haddock (Melanogrammus aeglefinus). ICES J. Mar. Sci. 63: 1096-1100.

Gillis, D. M., and Peterman, R. M. 1998. Implications of interference among fishing vessels and the ideal free distribution to the interpretation of CPUE. Can. J. Fish. Aquat. Sci. 55: 37-46.

Gillis, D. M., Peterman, R. M., and Tyler, A. V. 1993. Movement dynamics in a fishery: application of the ideal free distribution to spatial allocation of effort, Can. J. Fish. Aquat. Sci. 50: 323333.

Gregory, R. S., and Anderson, J. T. 1997. Substrate selection and use of protective cover by juvenile Atlantic cod Gadus morhua in inshore waters of Newfoundland. Mar. Ecol. Prog. Ser. 146: 9-20.

Hanchet, S. M., Blackwell, R. G., and Dunn, A. 2005. Development and evaluation of catch per unit effort indices for southern blue whiting (Micromesistius australis) on the Cambell Island Rise, New Zealand. ICES J. Mar. Sci. 62: 1131-1138.

Harley, S. J., Myers, R. A., and Dunn, A. 2001. Is catch-per-unit-effort proportional to abundance? Can. J. Fish. Aquat. Sci. 58: 1760-1772.

Hilborn, R., and Walters, C. J. 1992. Quantitative fisheries stock assessment: choice, dynamics and 
uncertainty. Chapman and Hall, New York.

Horwood, J., O’Brien, C., and Darby, C. 2006. North Sea cod recovery? ICES J. Mar. Sci. 63: 961968.

ICES 2006. Report of the working group on the assessment of demersal stocks in the North Sea and Skagerrak (WGNSSK). ICES CM 2006/ACFM:35

O’Brien, C. M., Fox, C. J., Planque, B., and Casey, J. 2000. Climate variability and North Sea cod. Nature 404: 142.

Paloheimo, J. E., and Dickie, L. M. 1964. Abundance and fishing success. Rapp. R-V. Reun. Cons. Int. Explor. Mer 155: 152-163.

Perry, A. L., Low, P. J., Ellis, J. R., and Reynolds, J. D. 2005. Climate change and distribution shifts in marine fishes. Science 308: 1912-1915.

Rindorf, A., and Lewy, P. 2001. Analyses of length and age distributions using continuation- ratio logits. Can. J. Fish. Aquat. Sci. 58: 1141-1152.

Rindorf, A., and Lewy, P. 2006. Warm, windy winters drive cod north and homing of spawners keeps them there. J. Appl. Ecol. 43: 445-453.

Rindorf, A., Jensen, H., and Schrum, C. 2007. Growth, temperature and density relationships of North Sea cod. In press, Can. J. Fish. Aquat. Sci.

Rose, G. A., and Kulka, D. W. 1999. Hyperaggregation of fish and fisheries: how catch-per-uniteffort increased as the northern cod (Gadus morhua) declined. Can. J. Fish. Aquat. Sci. 56 (S1): 118-127.

Rose, G. A., and Leggett, W. C. 1991. Effects of biomass-range interactions on catchability of migratory demersal fish by mobile fisheries: An example of Atlantic cod (Gadus morhua). Can. J. Fish. Aquat. Sci. 48: 843-848.

SAS Institute Inc. 2001. SAS version 8.12 [computer program]. SAS Institute Inc., Cary, North 
Carolina.

546 Swain, D. P., Nielsen, G. A., Sinclair, A. F., and Chouinard, G. A. 1994. Changes in catchability of 547 Atlantic cod (Gadus morhua) to an otter-trawl fishery and research survey in the southern $548 \quad$ Gulf of St Lawrence. ICES J. Mar. Sci. 51: 493-504.

549 Winters, G. H., and Wheeler, J. P. 1985. Interaction between stock area, stock abundance, and $550 \quad$ catchability coefficient. Can. J. Fish. Aquat. Sci. 42: 989-998.

551 Ulrich, C., and Andersen, B. S. 2004. Dynamics of fisheries, and the flexibility of vessel activity in Denmark between 1989 and 2001. ICES J. Mar. Sci. 61: 308-322. 
552 Table 1. Definition of Danish cod fishing fleets and cod related fisheries.

\begin{tabular}{lccccc}
\hline Fleet & $\begin{array}{c}\text { Vessel length } \\
(\mathrm{m})\end{array}$ & Gear & $\begin{array}{c}\text { Mesh size } \\
(\mathrm{mm})\end{array}$ & $\begin{array}{c}\text { Target } \\
\text { species** }\end{array}$ & $\begin{array}{c}\text { Avg. \% of total } \\
\text { Danish cod landings }\end{array}$ \\
\hline Danish small trawlers & $0-20$ & OTB/Pair trawl & $90-140$ & - & $5 \%$ \\
Danish large trawlers & $20-40$ & OTB/Pair trawl & $90-140$ & - & $16 \%$ \\
Danish small gillnetters & $0-20$ & Gillnet and line & $90-200$ & Cod & $36 \%$ \\
Danish large gillnetters & $20-40$ & Gillnet and line & $90-200$ & Cod & $9 \%$ \\
Danish Seine & All & Danish and Scottish seine & $90-150$ & - & $16 \%$ \\
\hline
\end{tabular}

553 *Defined as the most important species by value, -=not defined. ** Based on landings statistics

554 from 1990 to 2005

555 
556 Table 2. Correlation between catch per unit effort and total stock biomass $(T)$, spawning stock 557 biomass $(S)$ from stock assessment and total and mature cod survey catch rate within high density 558 areas. Values in parentheses denote probability of no correlation. Significant correlations $(\mathrm{P}<0.05)$ 559 are in bold.

\begin{tabular}{|c|c|c|c|c|c|}
\hline & \multirow[t]{2}{*}{ Quarter } & \multicolumn{2}{|c|}{ Stock } & \multicolumn{2}{|c|}{ High density survey } \\
\hline & & $T$ & $S$ & Total cod & Mature cod \\
\hline Danish small trawlers & 1 & $0.60^{(0.0023)}$ & $0.77^{(<0.0001)}$ & $0.72^{(<0.0001)}$ & $0.53^{(0.0089)}$ \\
\hline Danish small trawlers & 3 & $0.77^{(<0.0001)}$ & $0.84^{(<0.0001)}$ & & \\
\hline Danish large trawlers & 1 & $0.69^{(0.0002)}$ & $0.80^{(<0.0001)}$ & $0.84^{(<0.0001)}$ & $0.68^{(0.0003)}$ \\
\hline Danish large trawlers & 3 & $0.62^{(0.0014)}$ & $0.81^{(<0.0001)}$ & & \\
\hline English trawlers & All & $0.67^{(<0.0001)}$ & $0.53^{(0.0037)}$ & & \\
\hline Danish small gillnetters & 1 & $0.83^{(<0.0001)}$ & $0.90^{(<0.0001)}$ & $0.77^{(<0.0001)}$ & $0.67^{(0.0005)}$ \\
\hline Danish small gillnetters & 3 & $0.80^{(<0.0001)}$ & $0.86^{(<0.0001)}$ & & \\
\hline Danish large gillnetters & 1 & $0.73^{(<0.0001)}$ & $0.85^{(<0.0001)}$ & $0.77^{(<0.0001)}$ & $0.74^{(<0.0001)}$ \\
\hline Danish large gillnetters & 3 & $0.81^{(<0.0001)}$ & $0.77^{(<0.0001)}$ & & \\
\hline Danish seine & 1 & $0.29^{(0.1831)}$ & $0.189^{(0.3757)}$ & $0.34^{(0.1168)}$ & $0.17^{(0.4447)}$ \\
\hline Danish seine & 3 & $0.42^{(0.0484)}$ & $0.42^{(0.0489)}$ & & \\
\hline English seiners & All & $0.91^{(<0.0001)}$ & $0.79^{(<0.0001)}$ & & \\
\hline IBTS & 1 & $0.88^{(<0.0001)}$ & $0.88^{(<0.0001)}$ & & \\
\hline High density survey & 1 & $0.85^{(<0.0001)}$ & $0.77^{(<0.0001)}$ & & \\
\hline
\end{tabular}


Table 3. Probability of the parameters $b$ and $c$ being zero and final models (including only significant parameters) of catch per unit effort $(U)$ in either $\mathrm{kg} \cdot$ day $^{-1}$ (Danish fleets) or $\mathrm{kg} \cdot \mathrm{hour}^{-1}$ (English fleets and surveys) as a function of total stock $(T)$ or spawning stock $(S)$ biomass (both in $10^{9} \mathrm{~kg}$ ). Probabilities significant at the 0.05 -level are in bold. Values in parentheses denote standard error of the estimates.

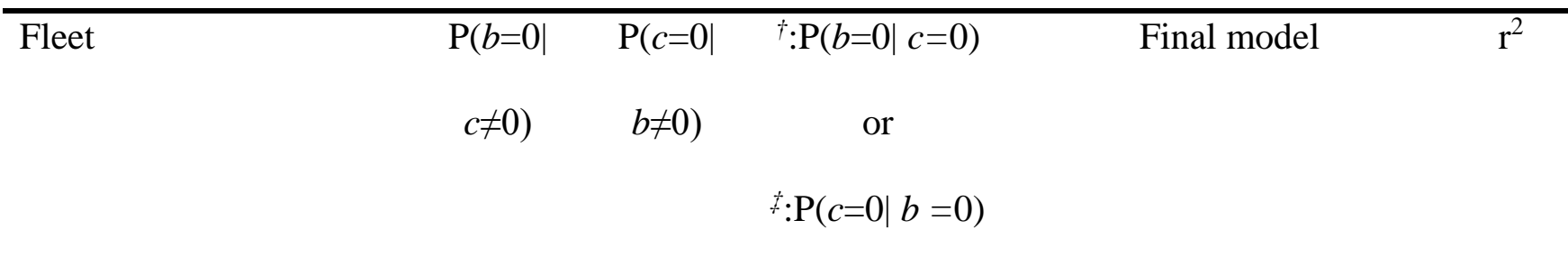

\section{Quarter 1}

Danish small trawlers

0.5063

0.2734

$0.1980^{\ddagger}$

$U=4.91^{(0.42)} S$

0.56

Danish large trawlers

$0.3060 \quad 0.4954$

$0.2689^{\dagger}$

$U=5.05^{(0.33)} S$

0.64

Danish small gillnetters

$0.2803 \quad 0.8825$

$<0.0001^{\dagger}$

$U=4.55^{(0.81)} S^{0.62^{(0.07)}}$

Danish large gillnetters

0.5242

0.9724

$0.0124^{\dagger}$

$U=8.26^{(2.12)} S^{0.71^{(0.10)}}$

Total cod survey catch

$0.5413 \quad 0.8036$

$0.1295^{\dagger}$

$U=0.348^{(0.017)} T$

rate in high density areas

Mature cod survey catch

$0.4357 \quad 0.5130$

$0.6177^{\dagger}$

$U=0.772^{(0.052)} S$

0.61

rate in high density areas

\section{Quarter 3}

Danish small trawlers

$0.7541 \quad 0.5770$

$\mathbf{0 . 0 4 8 8}^{\ddagger}$

$U=4.53^{(0.65)} S-0.110^{(0.054)}$

0.70

Danish large trawlers

0.1071

0.2624

$0.1090^{\dagger}$

$U=3.38^{(0.23)} S$

0.64

Danish small gillnetters

0.6435

0.7493

$0.0004^{+}$

$U=3.61^{(0.77)} S^{0.62^{(0.09)}}$

0.75

Danish large gillnetters

$0.7017 \quad 0.7069$

$\mathbf{0 . 0 0 0 9}^{\dagger}$

$U=4.27^{(1.14)} S^{0.56^{(0.11)}}$

0.60 


\section{Yearly average}

English trawlers

$0.5300 \quad 0.7296$

$0.1892^{\dagger}$

$U=0.117^{(0.009)} T$

0.43

English seiners

$<0.0001 \quad 0.0449$

$U=0.205^{(0.014)} T^{2.54^{(0.29)}}$

0.93

$+0.021^{(0.009)}$ 
569 Table 4. Trends (Pearson correlation coefficient with year) in latitude north (lat) and longitude east 570 (lon) of effort centre of gravity and correlation between survey and effort centre of gravity. Values 571 in parentheses denote probability of no correlation. Significant correlations are in bold.

\begin{tabular}{|c|c|c|c|c|c|c|c|c|}
\hline \multirow{3}{*}{ Fleet } & \multicolumn{4}{|c|}{ Trend } & \multicolumn{4}{|c|}{$\begin{array}{l}\text { Correlation between } \\
\text { survey and effort centre }\end{array}$} \\
\hline & \multicolumn{2}{|c|}{ Quarter 1} & \multicolumn{2}{|c|}{ Quarter 3} & \multicolumn{2}{|c|}{ Quarter 1} & \multicolumn{2}{|c|}{ Quarter 3a } \\
\hline & lat & lon & lat & lon & Lat & Lon & lat & Lon \\
\hline \multirow[t]{2}{*}{ Danish small trawlers } & 0.60 & 0.43 & -0.66 & 0.67 & 0.25 & 0.02 & -0.34 & -0.02 \\
\hline & $(0.0026)$ & $(0.0398)$ & $(0.0006)$ & $(0.0005)$ & $(0.2478)$ & $(0.9234)$ & $(0.2218)$ & $(0.9566)$ \\
\hline \multirow[t]{2}{*}{ Danish large trawlers } & 0.48 & 0.41 & 0.03 & 0.43 & 0.37 & 0.27 & 0.69 & 0.17 \\
\hline & $(0.0217)$ & $(0.0539)$ & $(0.9088)$ & $(0.0406)$ & $(0.0795)$ & $(0.2200)$ & $(0.0040)$ & $(0.5534)$ \\
\hline \multirow[t]{2}{*}{ Danish small gillnetters } & 0.65 & 0.97 & 0.50 & 0.88 & 0.63 & 0.59 & 0.72 & 0.30 \\
\hline & $(0.0007)$ & $(<0.0001)$ & $(0.0153)$ & $(<0.0001)$ & $(0.0014)$ & $(0.0030)$ & $(0.0028)$ & $(0.2728)$ \\
\hline \multirow[t]{2}{*}{ Danish large gillnetters } & 0.68 & 0.78 & -0.19 & 0.80 & 0.61 & 0.73 & -0.02 & 0.51 \\
\hline & $(0.0004)$ & $(<0.0001)$ & $(0.3877)$ & $(<0.0001)$ & $(0.0019)$ & $(<0.0001)$ & $(0.9563)$ & $(0.0522)$ \\
\hline \multirow[t]{2}{*}{ Danish seine } & 0.77 & 0.29 & 0.05 & -0.11 & 0.74 & 0.41 & 0.49 & 0.35 \\
\hline & $(<0.0001)$ & $(0.1855)$ & $(0.8109)$ & $(0.6021)$ & $(<0.0001)$ & $(0.0538)$ & $(0.0611)$ & $(0.1991)$ \\
\hline \multirow[t]{2}{*}{ Survey } & 0.73 & 0.55 & 0.76 & 0.23 & & & & \\
\hline & $(<0.0001)$ & $(0.0050)$ & $(0.0011) \mathrm{a}$ & $(0.4103) \mathrm{a}$ & & & & \\
\hline
\end{tabular}




\section{Figure captions}

573 Fig. 1. Study area. Small rectangles are ICES statistical rectangles.

574 Fig. 2. Relationship between catch per unit effort $(U)$ and biomass $(B)(a)$ and catchability $(U / B)(b)$ 575 for different parameterisations of the model $U=a B^{(1+b)}+c . \mathbf{\square}: b=c=0 ; \boldsymbol{\Delta}: b=0, c>0 ; \bullet: b=0, c<0$;

: $0<b<1 ; c=0$ and $\square: b>0, c=0$.

Fig. 3. Temporal development in North Sea cod total stock biomass (solid line) and spawning stock biomass (broken line).

Fig. 4. Temporal development in yearly effort ( $\mathrm{a}$ and $\mathrm{b}$ ) and yearly average catch per unit effort (c and d) of the seven fleets examined. Right axis refers to Danish fleets, left axes to English fleets. a and c: Danish small trawlers (+), Danish large trawlers ( $\mathbf{a})$, and English trawlers $(\mathbf{\Delta})$. b and d: Danish small gillnetters ( $\mathbf{\Delta})$, Danish large gillnetters $(\times)$, Danish seine $(\boldsymbol{\varpi})$ and English seine $(+)$.

Fig. 5. Cod catch composition of the different fleets (yearly average by weight). Mature ( $\boldsymbol{\square})$, mixed mature and immature $(\square)$ and immature $(\square)$ cod. A: Danish small trawlers, B: Danish large trawlers and G: English seine.

Fig. 6. Relationship between catch per unit effort and stock biomass (a and b) or spawning stock 588 biomass (c, d, e, f and g). Values for Danish fleets refer to the $1^{\text {st }}$ quarter. English trawlers (a), 589 English seniers (b), Danish small trawlers (c), Danish large trawlers (d), Danish small gillnetters (e), 590 Danish large gillnetters (f) and Danish seine (g). Lines are fitted models (se Table 3) for all fleets 591 except Danish seiners where a linear regression was used (no model was fitted for this fleet).

592 Fig. 7. Relationship between catchability and stock biomass (a and b) or spawning stock biomass (c, d, e, f and g). English trawlers (a), English seniers (b), Danish small trawlers in the first quarter (c), 
594 Danish small trawlers in the third quarter (d), Danish small gillnetters in the first quarter (e) and 595 Danish large gillnetters in the first quarter (f). Lines are catchabilities estimated as predicted catch 596 per unit effort from fitted models (se Table 3) divided by biomass.

597 Fig. 8. Residuals of fitted models (observed catch per unit effort-model predicted catch per unit 598 effort). a: English trawlers $(\Delta)$ and seiners $(\Delta)$, b: Danish small $(\Delta)$ and large $(\Delta)$ trawlers and c: 599 Danish small $(\triangle)$ and large $(\Delta)$ gillnetters.

600 Fig. 9. Relationship between survey catch rate of all (a) and mature (b) cod in high density areas 601 and total stock (a) and spawning stock biomass (b). Lines are fitted models (se Table 3).

602 Fig. 10. Relationship between harvest rate (yearly landings/stock biomass) and stock biomass. a: 603 English ( $\Delta$ and $\Delta$ ) and Scottish ( $\square$ and $\boldsymbol{\square}$ ) landings and b: Danish ( $\Delta$ and $\Delta$ ) and other 604 international ( $\square$ and $\boldsymbol{\square}$ ) landings. Solid and empty symbols denote the period before and after the 605 introduction of restrictive quotas in 2001, respectively. Lines are linear regressions for the period 606 before 2001. 


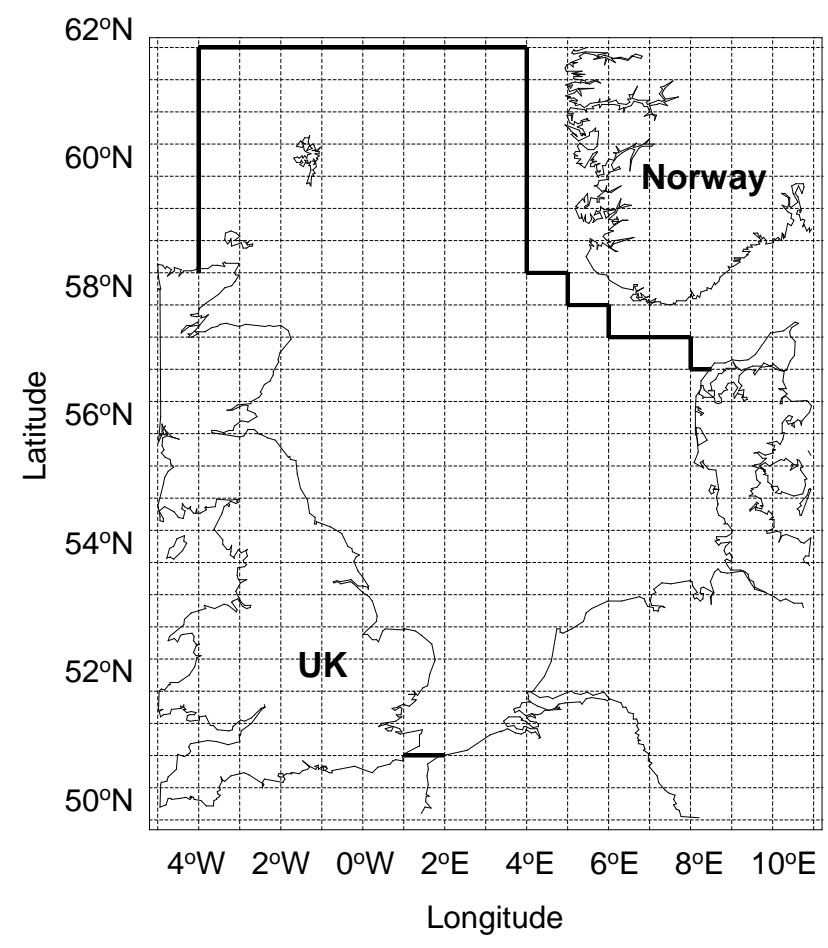



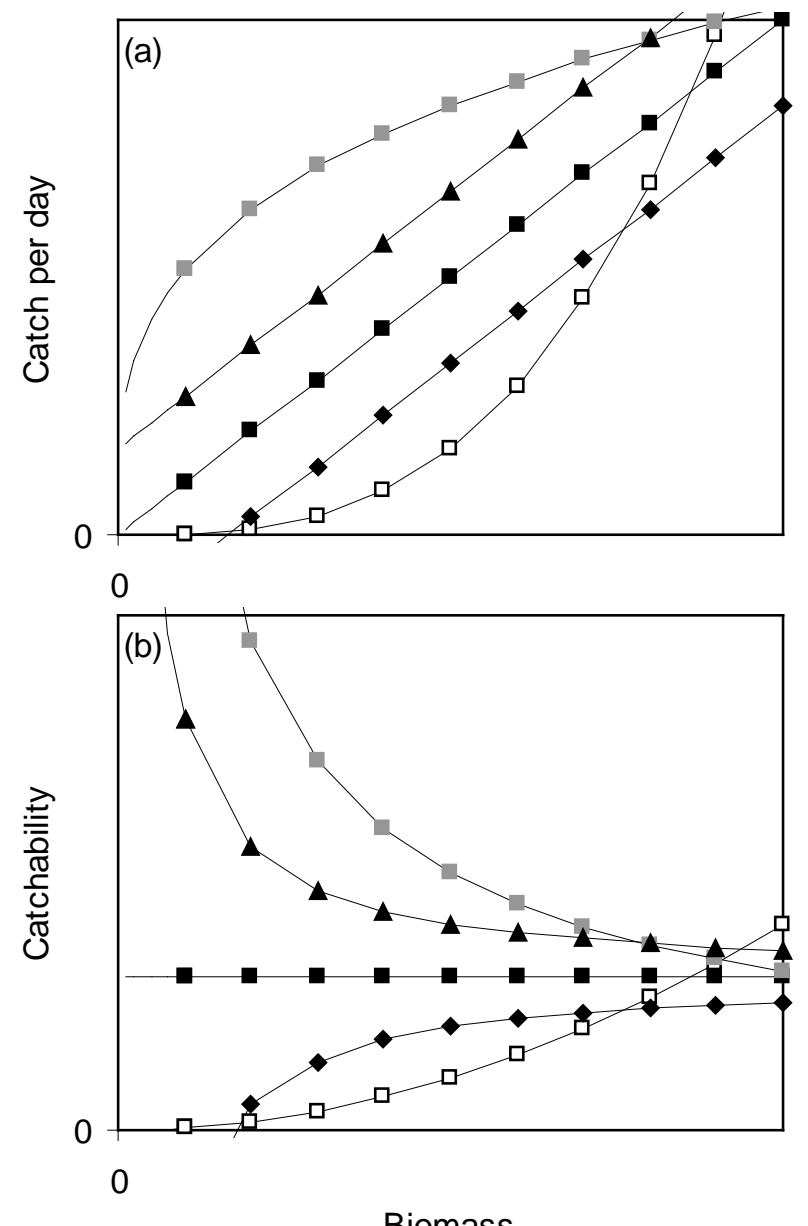

Biomass 


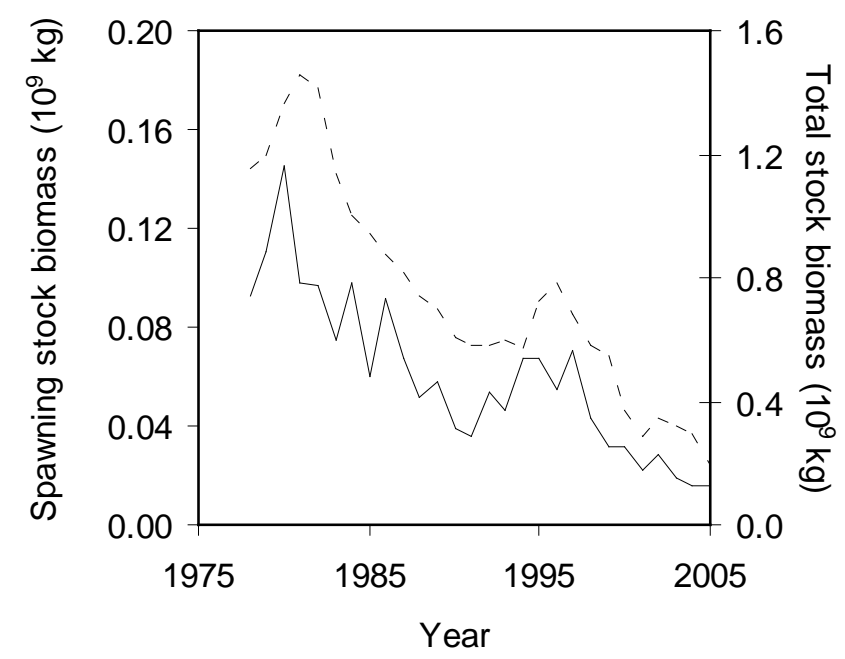



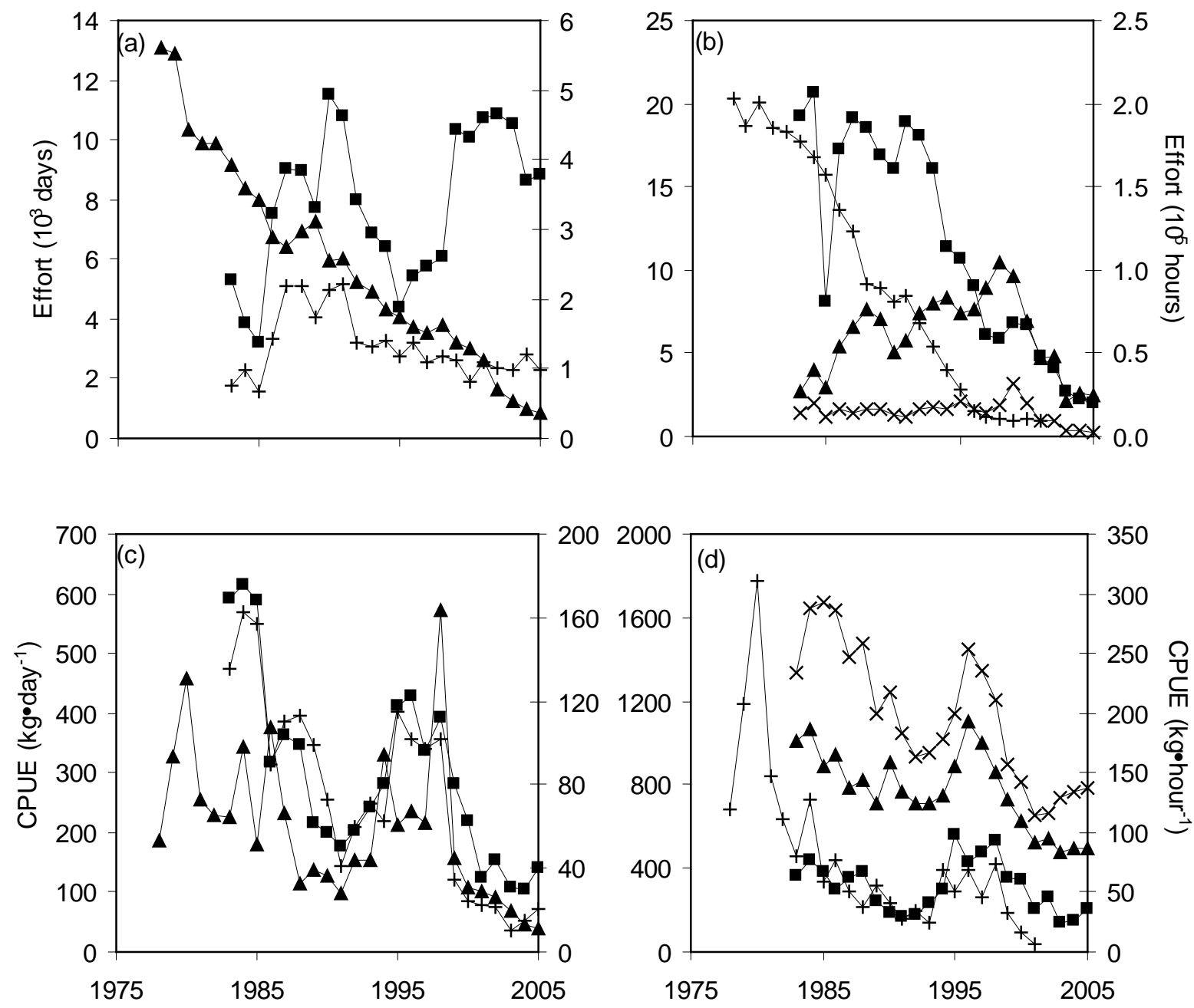

Year 


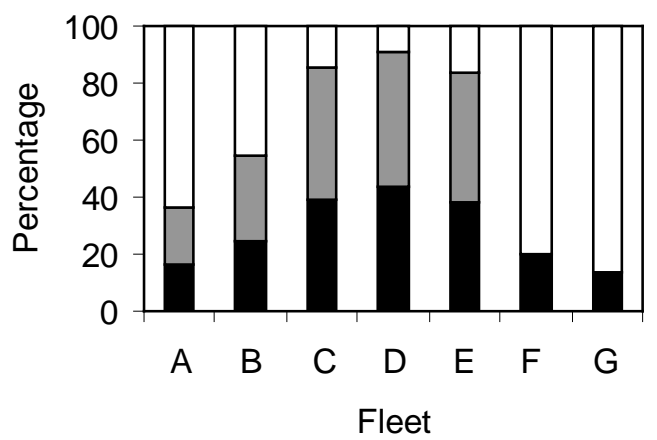



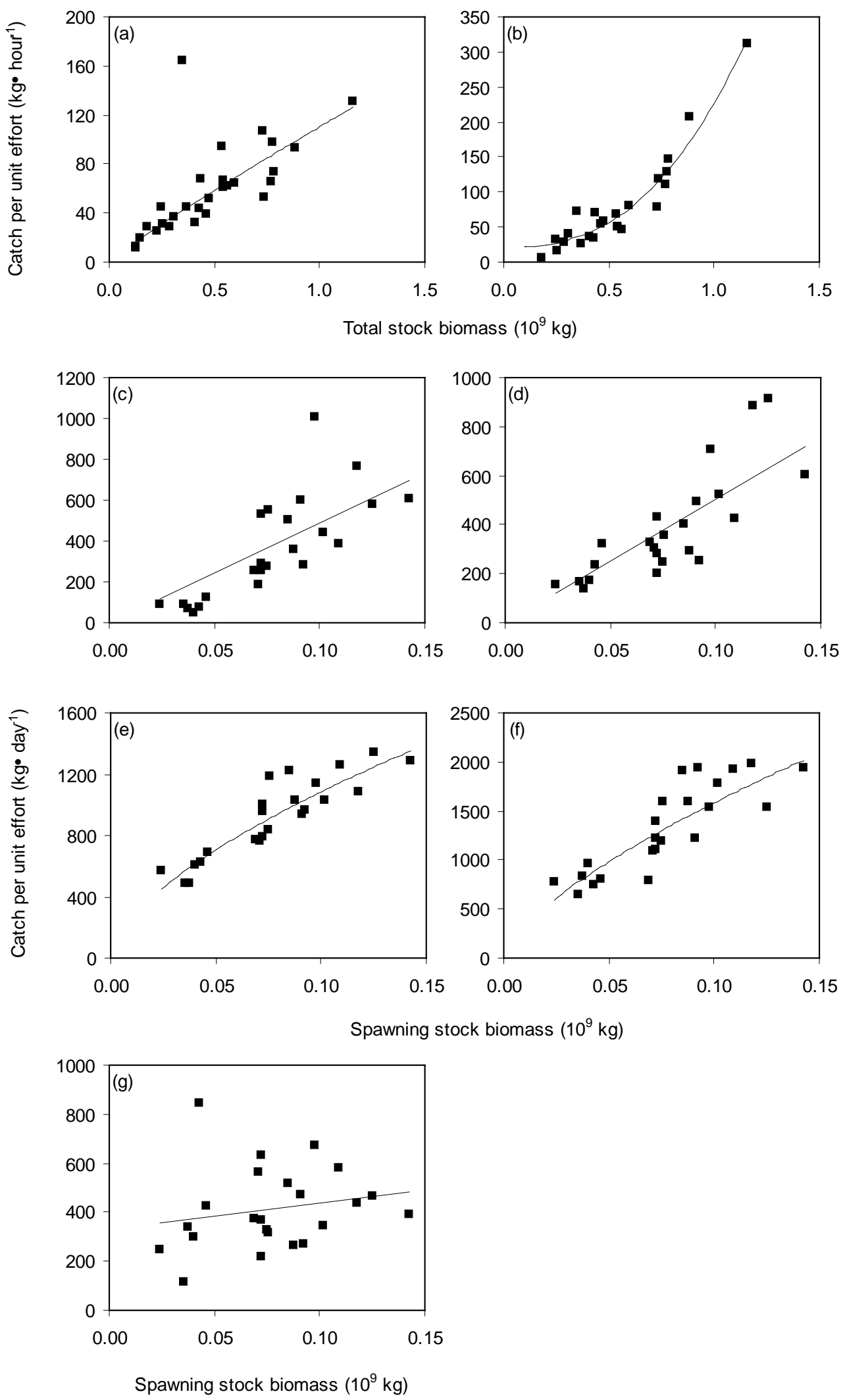

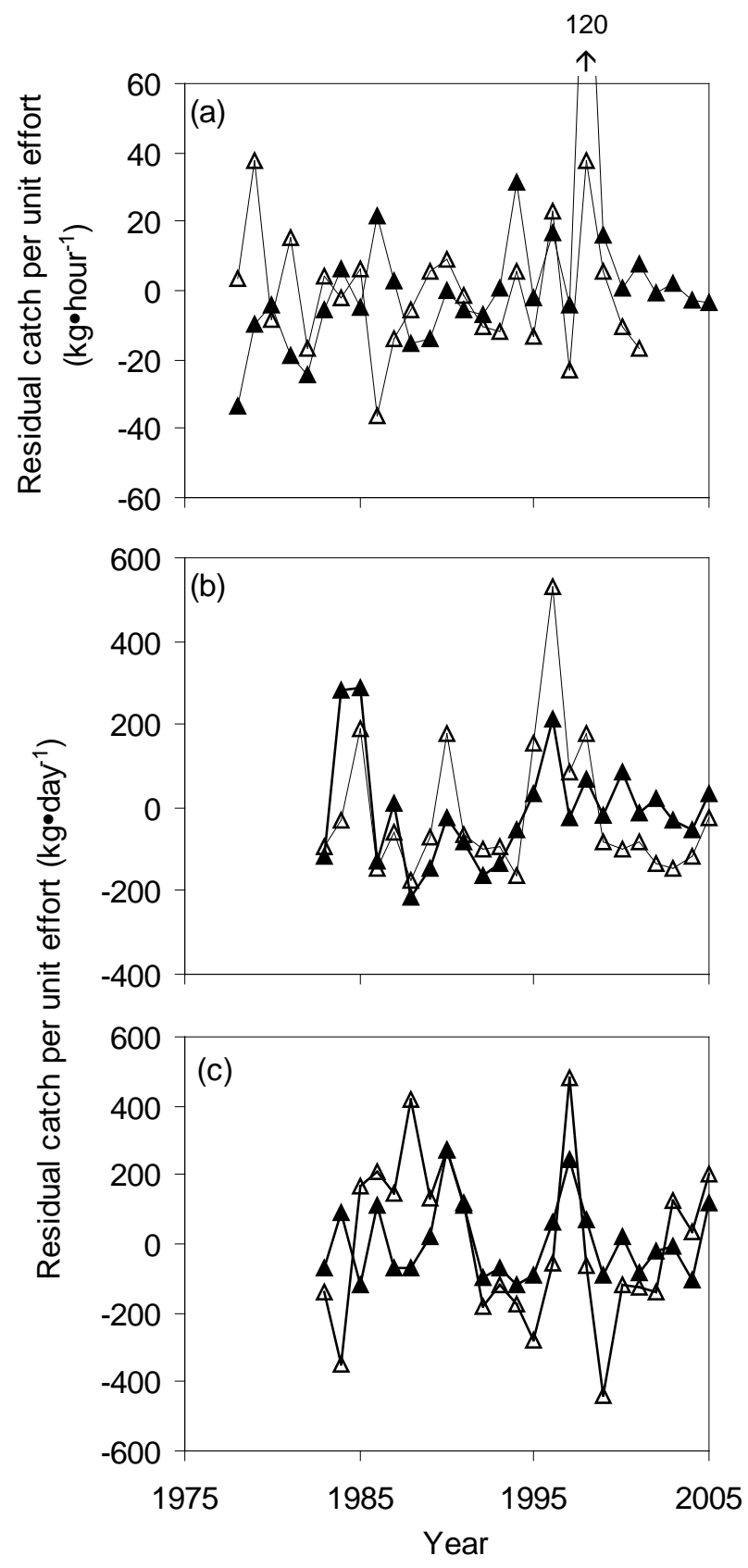


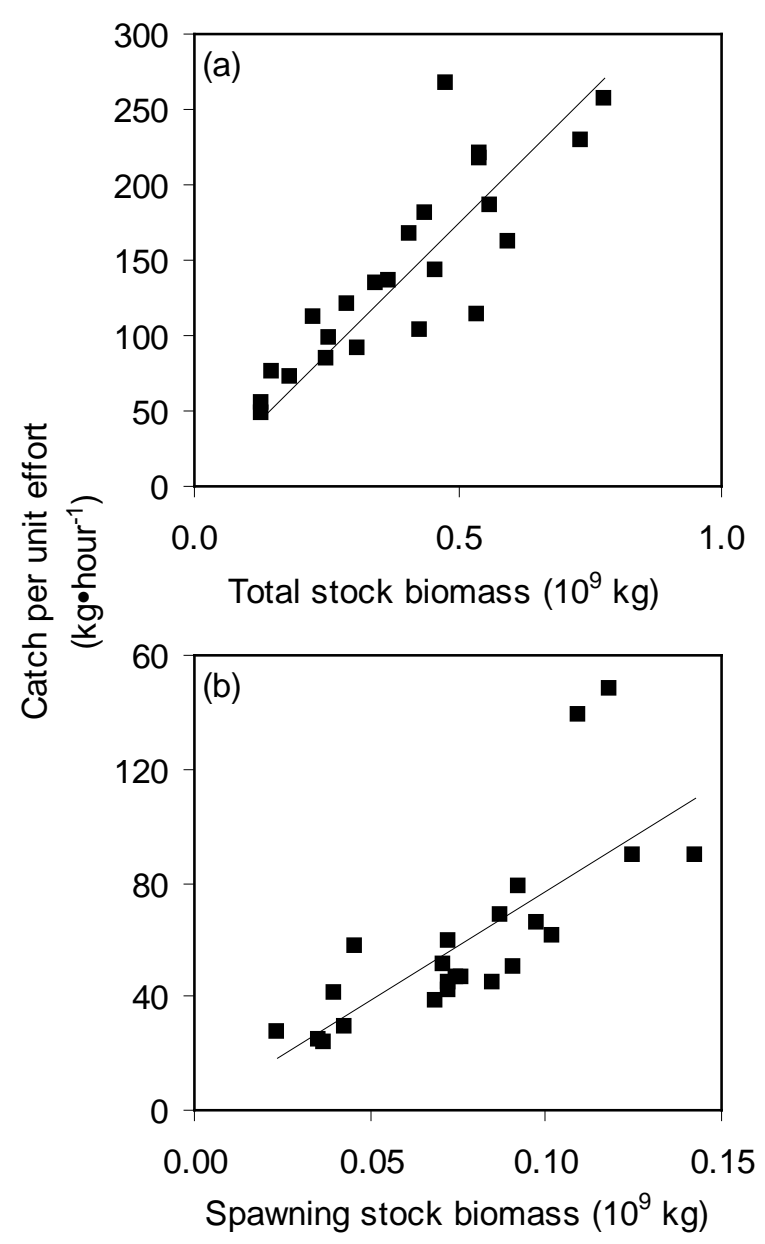




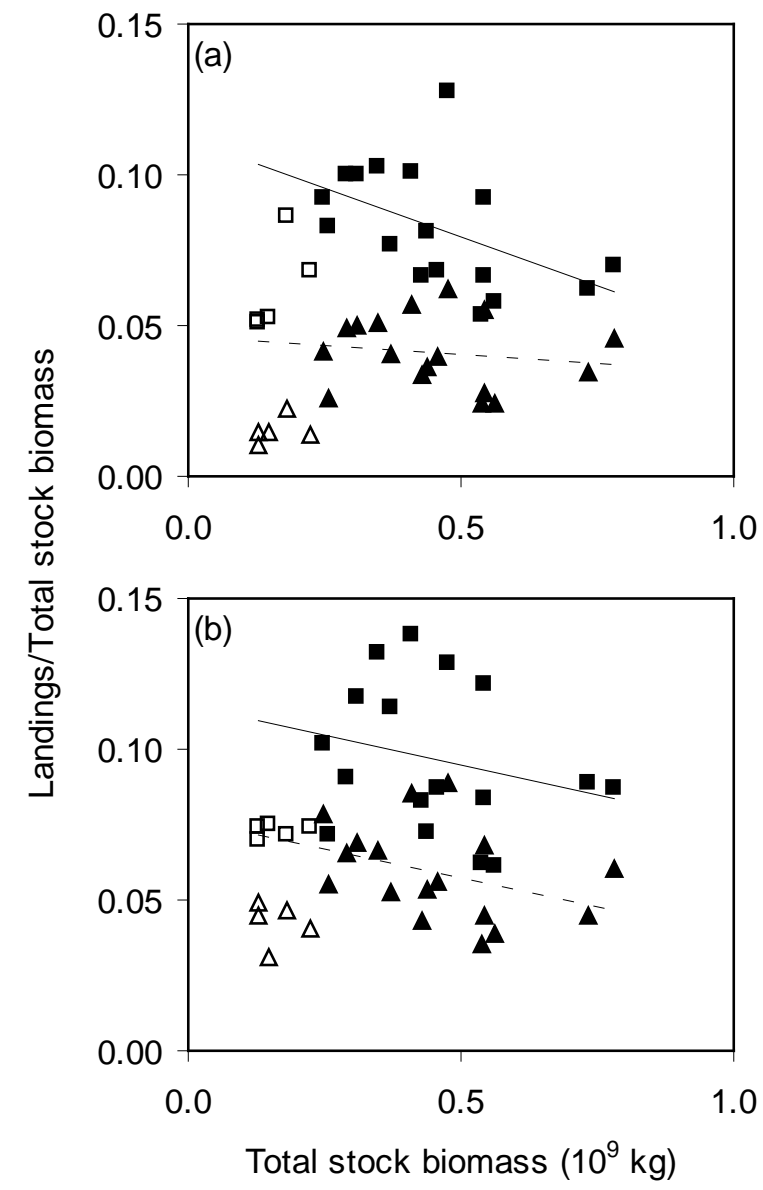

